\title{
pro.posições
}

$e$-ISSN 1980-6248

http://dx.doi.org/10.1590/1980-6248-2017-0067

LEITURAS E RESENHAS

\section{Transformação do espaço: a poética na ação de crianças e jovens ${ }^{1}$}

\section{Space transformation: the poetics of the actions of children and young people}

Aitken, Stuart. The ethnopoetics of space and transformation: young people's engagement, activism and aesthetics. Farnham: Ashgate Publishing Limited, 2014.

Rhaisa Naiade Pael Farias (i)

(i) Universidade de Brasilia - UnB, Brasília, DF, Brasil. https://orcid.org/0000-0002-3952-8422, rhaisapael@gmail.com

Stuart Campbell Aitken lançou em 2014 The ethnopoetics of space and transformation: young people's engagement, activism and aesthetics, destacando a estética poética das ações políticas infantis e explorando as emoções que as sustentam. O livro compila as pesquisas realizadas pelo autor ao longo de quase trinta anos e em quatro continentes, entretanto, não é destinado apenas a fins acadêmicos, mas a todos aqueles que acreditam na possibilidade efetiva do exercício da cidadania para a transformação de sua comunidade por meio de ações em nível local.

Aitken é geógrafo formado pela University of Glasgow (1980), mestre em Geografia pela Miami University - Obio (1981) e doutor em Geografia pela Western University (1985). Atualmente é professor titular de Geografia da San Diego State University e diretor do Center for Interdisciplinary Studies of Youth and Space. Possui uma extensa produção de temas ligados à Geografia Humana e têm como ênfase pesquisas em área urbana com famílias e comunidades, crianças e jovens.

Nesta obra o autor propõe a quebra do paradigma que considera crianças como passivas, sujeitas à proteção e cuidado do adulto. Ao evidenciar as ações políticas de reivindicação,

\footnotetext{
${ }^{1}$ Apoio: Coordenação de Aperfeiçoamento de Pessoal de Nível Superior - CAPES
} 


\section{pro.posições}

$e$-ISSN 1980-6248

http://dx.doi.org/10.1590/1980-6248-2017-0067

protesto e ruptura em questões que tangem suas vidas, são encaradas como capazes de provocar mudanças na sociedade e nos espaços por meio de sua forma peculiar de estar no mundo.

Para embasar seus argumentos, lança mão de autores da Filosofia, Geografia, Sociologia e Literatura, criando conexões interdisciplinares entre espaço, cidadania, estética e emoções. Aitken define espaço não como um palco estático, mas onde complexas relações acontecem; a cidadania como ação criativa e de ressignificação; a estética indo além do belo e sendo a ruptura com aquilo que é facilmente perceptível; e as emoções como os sentimentos que afetam nossa forma de ver, ser e estar no mundo e que impulsionam ações políticas. Consequentemente, espaços e pessoas transformam-se mediante relações afetivas e estéticas no exercício de sua cidadania, reapropriando-se do espaço urbano.

Neste sentido, a cidade volta a ser espaço de convivência, experiência e aprendizagem intra e intergeracional. E é na poética da vida de crianças e jovens que novas formas de cidadania acontecem, por meio de deslocamentos e ativismo político em uma (re)tomada do território urbano, e uma (re)invenção de cartografias que materializam espacialidades livres e fluídas.

A obra de Aitken contém um prefácio, seguido de oito capítulos, e está organizada em duas partes. A primeira reúne uma discussão baseada em teorias espaciais a respeito de eventos de mudança e engloba os quatro primeiros capítulos. Em "Birthing the poetics of space and transformation e Ethnopoetics", o autor apresenta as bases teóricas que fundamentam suas pesquisas com a discussão sobre espaço e mudança e a definição da Ethnopoetry. Na sequência, o capítulo "Disrupting spatial competencies and affordances" exemplifica a maneira subversiva como crianças com paralisia cerebral superam obstáculos diários relacionados a acessibilidade e mobilidade enfrentadas em uma cidade nos Estados Unidos. O capítulo "Development, figured worlds and affective ecologies" aborda como jovens e suas famílias nativas da província de Guizhou/China resistem, enfrentam e protestam contra as mudanças ambientais e de desenvolvimento radicais provocadas pelo governo em sua região.

A segunda parte retrata e debate experiências de jovens que por meio de sua participação cívica foram capazes de desencadear transformações políticas e esperança na sociedade. $O$ capítulo "Schoolyards, violence and landscapes of revolution", dentre outros assuntos, trata de como no Chile, durante a revolução dos Pinguinos, estudantes saíram às ruas da cidade para protestar contra práticas neoliberais na educação. No capítulo “Children’s work, civic 


\section{pro.posıções}

$e$-ISSN 1980-6248

http://dx.doi.org/10.1590/1980-6248-2017-0067

responsibilities and refashioning citizenship", uma pesquisa realizada nos Estados Unidos demonstra o potencial de ação dos filhos de ativistas latinas em processos de engajamento civil contra uma medida que restringe traduções verbais do espanhol para inglês em lugares formais aos familiares e membros da comunidade. Já em "Poets and stateless children", uma parcela da população eslovena que foi decretada como apátrida, conhecida como Iz̧brisani, após anos de represálias e medo, protestou em prol da conquista de um status legal no país e por novas formas de nacionalismo. A participação das crianças nesses protestos deu-se pela sua presença durante as ações, como quando, em 2006, marcharam rumo ao Tribunal Europeu dos Direitos Humanos em Estrasburgo.

Finalmente, o autor conclui seu livro com o capítulo "The poetic aesthetics of children's politics", reformulando a noção de espacialidade e mudança a partir de La- clau, De Certeau, Massey, Rancière, Žižek e Agamben. Aitken (p. 193); explica que, se tomarmos o espaço como “precursor político, bem como importante produto do político, então... deve haver um deslocamento, uma liberação da cartografia, sendo esta uma moldura para possibilidades, uma materialização espacial fluída e surpreendente”. Com essa compreensão a interação entre espaço, comunidade e identidade não está engessada a questões institucionais e estruturais, mas propulsiona atos que rompem o status quo, e impulsionam a transformação.

De maneira lírica e poética, Aitken, ao compilar transcrições de entrevistas, observações participantes, metodologias visuais e brincadeiras, cunha sua própria metodologia de escrita, chamada Ethnopoetry. Esta técnica consiste no uso de imagens e na transformação da fala dos participantes da pesquisa em versos, assim, realça ao mesmo tempo suas identidades e especialidades, representando parte daquilo que seria irrepresentável, estimulando as emoções do leitor para além do texto escrito.

O livro pode ser ainda uma grande fonte de inspiração para o desenvolvimento de pesquisas inovadoras com a participação efetiva das crianças, pois demonstra como a permanência no campo, a construção de relacionamento entre pesquisador e participante e a utilização de métodos alternativos que não priorizem o discurso oral, são essenciais em um processo sensível que vê, escuta, sente e toca o outro, e mais, valoriza os pontos de vista das crianças e jovens enquanto análise autêntica e relevante na pesquisa. 


\section{pro.posıções \\ $e$-ISSN 1980-6248}

http://dx.doi.org/10.1590/1980-6248-2017-0067

O que nos chama atenção na compilação dos estudos do autor é como as vozes, experiências e ações das crianças e jovens são capazes de revolucionar e desencadear transformações reais na sociedade. Essas diferentes possibilidades de interação no e com o espaço urbano, a partir de processos pessoais e sociais, criam sentidos, significados e sentimentos, por se envolverem e serem envolvidas ativamente em suas causas, superando, assim, as estratégias institucionais e molduras espaciais que tentam abafar suas ações políticas.

Tal pressuposto já vem sendo utilizado por outros autores, como os geógrafos Bosco e Joassart-Marcelli (2015), que apoiados nos estudos de Aitken retratam a colaboração, a agência e a capacidade das crianças de participarem politicamente nas decisões que afetam sua qualidade de vida. Eles relatam a colaboração de crianças no planejamento de uma proposta de área verde em uma cidade da Califórnia, nos Estados Unidos, onde ajudaram a evitar a criação de ambientes infantis a partir de uma perspectiva adulta e, assim, foram capazes de produzir uma mudança positiva no projeto por meio de suas interpretações e engajamento emocional com o espaço.

Concluímos, portanto, que a temática do livro é atual e relevante para diferentes áreas do conhecimento. Ao mesmo tempo é provocativa por instigar a criação de uma agenda de pesquisas que considere as ações de crianças e jovens como políticas e transformativas. Como exemplo, temos as recentes ocupações de escolas e faculdades que jovens brasileiros realizaram para reivindicar e fortalecer o respeito à democracia e conquistas sociais que parecem estar sendo descontruídas atualmente no país.

\section{Referências}

Bosco, F. J.; Joassart-Marcelli, P. (2015). Participatory planning and children's emotional labor in the production of urban nature. Emotion, Space and Society, 16, 30-40.

Submetido à avaliação em 11 de abril de 2017; aceito para publicação em 22 de maio de 2017. 